\title{
Vaginal Gossypiboma In A 3 Year Old Female Child- A Case Report and Literature Review
}

\author{
Waqas Ahmad*1, Memoona Mian², Iram Zaheer ${ }^{3}$, Muhammad Umer Nasir ${ }^{1}$ and Amjad Iqbal ${ }^{1}$ \\ ${ }^{1}$ Department of Radiology, Shaukat Khanum Memorial Cancer Hospital and Research Center Lahore, Pakistan \\ ${ }^{2}$ Department of Radiology, University of Arkansas for Medical Sciences, AR, USA \\ ${ }^{3}$ Department of Radiology, Armed Forces, KSA
}

*Corresponding author: Waqas Ahmad, Department of Radiology, Shaukat Khanum Memorial Cancer Hospital and Research

Center Lahore, Pakistan

\section{ARTICLE INFO}

Received: 幽 April 24, 2019

Published: 幽 May 03, 2019

Citation: Waqas Ahmad, Memoona Mian, Iram Zaheer, Muhammad Umer Nasi, Amjad Iqbal. Vaginal Gossypiboma In A 3Year Old Female Child- A Case Report and Literature Review. Biomed J Sci \& Tech Res 17(4)-2019. BJSTR. MS.ID.003046.

ABSTRACT

Gossypiboma is a term used to describe foreign objects, often surgical sponges / swabs that are left accidentally in the body during a surgical procedure. Diagnosing these remains tricky and challenging for radiologists due to their variable presentations and imaging appearances. Lack of diagnosis can result in serious complications ranging from infection to death. Vaginal foreign bodies have been described in detail in the past literature in the adult population. We present an unusual case of a vaginal gossypiboma in a female child who had an initial diagnosis of vaginal rhabdomyosarcoma and was subsequently found to have a vaginal mass after treatment which remained misdiagnosed during multiple initial followups. An eventual diagnosis of a gossypiboma was made on vaginoscopic removal of the surgical gauze.
\end{abstract}

Keywords: Oncology; Pediatric; Gossypiboma

\section{Introduction}

Retained surgical sponges are seldom reported due to medicolegal implications. Awareness of this problem is not only mandatory for the surgeons but is crucial for the radiologists so as to make prompt and accurate diagnosis in such cases. A gossypiboma, textiloma [1] or cottonoid are the common terms used to describe such foreign objects (a mass of cotton matrix or a sponge) that are left behind in a body cavity during a surgical procedure. The manifestations and complications of gossypibomas are variable, hence diagnosis can be difficult and patient morbidity is significant [1]. The incidence of retained surgical instruments is estimated at 1 in 100-3000 of all surgical interventions and 1 in 1000-1500 for all intrabdominal operations [2-4].

\section{Case Report}

We report the case of a 3-year-old female child who presented to the outpatient walk in clinic at our institution with a history of a vaginal mass noted by her parents for for 6 months. She underwent surgical resection of the mass by a surgeon at an outside facility. Histopathology was consistent with vaginal embryonal rhabdomyosarcoma. She was admitted to our institution and on baseline work up, a residual mass was identified on the MRI pelvis. Completion surgery followed by brachytherapy was the proposed treatment after Multidisciplinary Tumor Board discussion. She underwent repeat resection of the residual mass (which was resected in two fragments according to the operative report) followed by brachytherapy. Further chemotherapy was planned and given according to low risk regimen of rhabdomyosarcoma. The child subsequently presented after 4 months after chemo with vaginal discharge. Repeat MR imaging demonstrated a heterogeneous abnormality in the region of vaginal vault and upper half of the vagina which was thought to represent thick inspissated serosanguinous secretions secondary to radiation related vaginal stenosis versus noncontiguous tumor recurrence (Figure 1). 

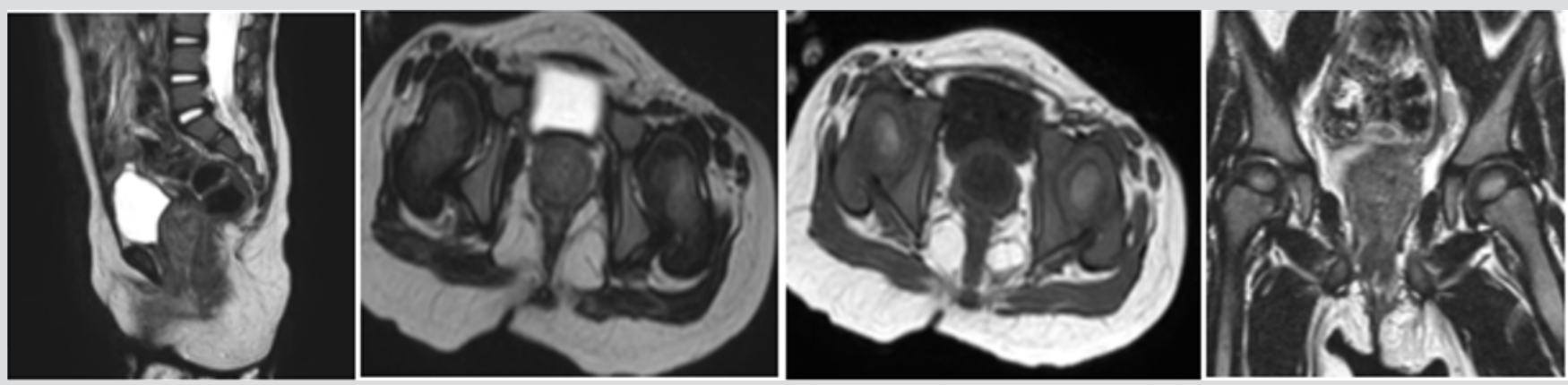

Figure 1: Sagittal(a) and axial (b) T2W images showing heterogenous mass like signal changes in vaginal canal thought to be secretions or disease. Similar changes noted on axial (c) and coronal (d) T1WI. It finally proved to be a gossypiboma on vaginoscopy/ pathology.

Examination under anesthesia was suggested. Cyst vaginoscopy was performed. On per operative findings a large foreign body was seen in vagina with minor ulcerations. No residual thickening of vaginal wall and no evidence of any residual tumor was seen.
Removal of the foreign body was performed, which turned out to be surgical gauze. Post procedure imaging showed complete removal of gauze (Figure 2). Histopathology suggested a gossypiboma which was left inside at the time of brachytherapy.
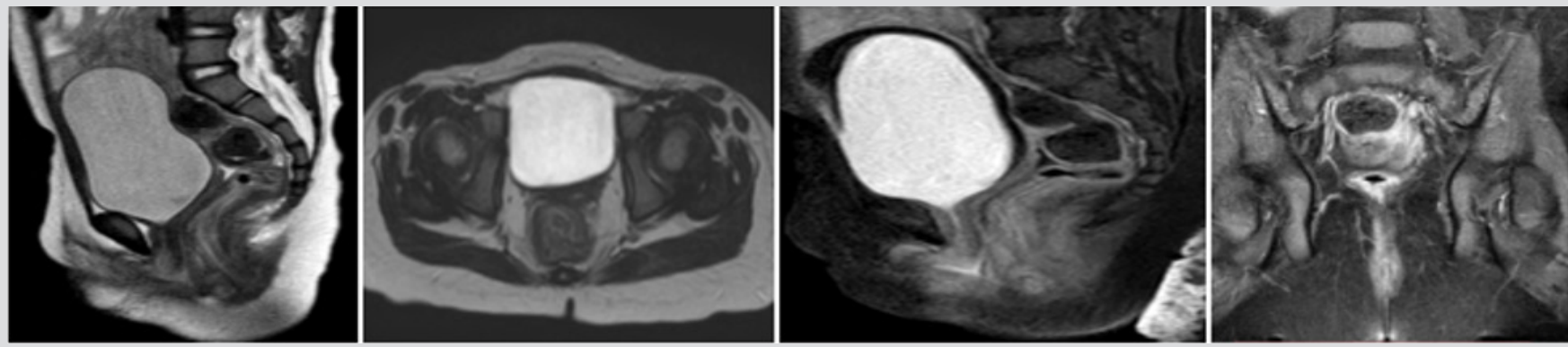

Figure 2: Sagittal (a) and axial (b)T2W images showing normal vaginal canal after removal of the gossypiboma. Post contrast sagittal (c) and coronal (d) T1WI Fat Sat show normal signal without any abnormal enhancing lesion or disease recurrence.

\section{Discussion}

Several cases of retention of surgical gauze after surgical procedures have been reported in literature; however, many remain unreported due to fear of litigation [1]. Forgotten gauze has been known to migrate to several hollow intra-abdominal organs such as intestine, stomach, and thoracic cavity [1-11]. Different foreign bodies have been forgotten, transported, or left accidentally in the adult vagina over a period of time. Such objects included tampons, bottle caps, sex toys, and sometimes dangerous substances like batteries and illicit drugs [3]. To our knowledge, a case of a vaginal gossipiboma in a pediatric patient is a rare occurrence. Pathologically, two types of foreign-body reaction can occur. The first is an aseptic fibrinous response that creates adhesions and encapsulation. The second response is exudative in nature and leads to abscess formation with or without secondary bacterial invasion [6]. In an experimental animal study to evaluate the process of migration of gossypiboma; four stages ware described.

These are foreign-body reaction, secondary infection, mass formation, and remodeling. Plain radiography and computed tomography (CT) can diagnose most cases of gossypiboma.
However, MRI is useful in differentiating a foreign body from an abscess $[1,3,9,12,13]$. Malignant transformation has been reported following long-standing irritation from gossypiboma resulting in hematoma, granulomatous inflammation, abscess formation cystic masses, and/or neoplasm [12,13]. The treatment options for gossypiboma depend on the size, location, complications, and facilities available; ranging from laparoscopic retrieval to open surgery [14-16]. Uncomplicated gossypiboma can be retrieved laparoscopically. However, migration to hollow organs requires exploration, removal of the foreign body, followed by resection, and/or repair of the perforated organs, toileting, and sometimes drainage of the cavity.

\section{Conclusion}

The radiologist should almost always consider the possibility of a retained sponge in imaging of every postoperative case including the pediatric patient population. This is even more important in patients with unusual presentations and or radiological imaging findings. A high degree of suspicion is important for preoperative diagnosis. Despite the use of radio-opaque sponges and thorough sponge counting, this dreaded mishap still occurs. Although human 
errors cannot be completely abolished, continuous medical training and strict adherence to regulations should reduce the incidence to a minimum.

\section{References}

1. Lin TY, Chuang CK, Wong YC, Liao HC (1999) Gossypiboma: Migration of retained surgical gauze and spontaneous transurethral protrusion. BJU Int 84: 879-880.

2. Leppaniemi AK (1991) Intravesical foreign body after inguinal herniorrhaphy: Case Report. Scand J Urol Nephrol 25(1): 87-88.

3. Nwosu EC, Rao S, Igweike C, Hamed H (2005) Foreign objects of long duration in the adult vagina J Obstet Gynaecol 25(7): 737-739.

4. Disu S, Wijesiriwardana A, Mukhtar H, Eben F (2007) An ileal migration of a retained surgical swab (gossypiboma): A rare cause of an epigastric mass. J Obstet Gynaecol 27(2): 212-213.

5. Ojo BA, Umobong EO, Ibrahim IO, Ezemamma JC, Fasoranti TO, et al. (2013) Gossypiboma: Twelve years there-after. Int J Trop Dis Health 3(3): 184-189.

6. Erbay G, Koç Z, Calipkan K, Araz F, Ulusan S (2012) Imaging and clinical findings of a gossypiboma migrated into the stomach. Turk J Gastroenterol 23(1): 54-57.

7. Malhotra MK (2012) Migratory surgical gossypiboma-cause of iatrogenic perforation: Case report with review of literature. Niger J Surg 18(1): 27 29.

\section{ISSN: 2574-1241}

DOI: 10.26717/BJSTR.2019.17.003046

Waqas Ahmad. Biomed J Sci \& Tech Res

(c) (i) This work is licensed under Creative

Submission Link: https://biomedres.us/submit-manuscript.php
8. Lone GN, Bhat AH, Tak MY, Garcoo SA (2005) Transdiaphragmatic migration of forgotten gauze sponge: An unreported entity of lung abscess. Eur J Cardiothorac Surg 28(2): 355-357.

9. Ugochukwu AI, Edeh AJ (2011) Retained intra-abdominal artery forceps - An unusual cause of intestinal strangulation. N Am J Med Sci 3(7): 339343.

10. Akbulut S, Sevinc MM, Basak F, Aksoy S, Cakabay B (2009) Transmural migration of a surgical compress into the stomach after splenectomy: A case report. Cases J 2: 7975

11. Gencosmanoglu R, Inceoglu R (2003) An unusual cause of small bowel obstruction: Gossypiboma - case report. BMC Surg 3: 6 .

12. Kaplan M, Iyiköpker HI (2012) A new complication of retained surgical gauze: Development of malignant fibrous histiocytoma - report of a case with a literature review. World J Surg Oncol 10: 139.

13. Lata I, Kapoor D, Sahu S (2011) Gossypiboma, a rare cause of acute abdomen: A case report and review of literature. Int J Crit Illn Inj Sci $1(2): 157-160$.

14. Mohammad MA, Chukwuemeka AL, Aji SA, Tukur J, Diggol GI, et al. (2014) Intravesical migration of gossypiboma following vaginal hysterectomy: An unusual cause of acute urinary retention. Arch Int Surg 4(3): 176179.

$\begin{array}{ll}\text { BIOMEDICAL } & \text { Assets of Publishing with us } \\ \text { RESEARCHES } & \text { - Global archiving of articles } \\ \text { ISSN: 2574-1241 } & \text { - Immediate, unrestricted online access } \\ & \text { - Rigorous Peer Review Process } \\ \end{array}$

